\title{
Size-dependent in vivo toxicity of PEG-coated gold nanoparticles
}

This article was published in the following Dove Press journal:

International Journal of Nanomedicine

19 September 2011

Number of times this article has been viewed

\section{Xiao-Dong Zhang \\ DiWu \\ Xiu Shen \\ Pei-Xun Liu \\ $\mathrm{Na}$ Yang \\ Bin Zhao \\ Hao Zhang \\ Yuan-Ming Sun \\ Liang-An Zhang \\ Fei-Yue Fan}

Institute of Radiation Medicine, Chinese Academy of Medical Sciences and Peking Union Medical College, Tianjin Key Laboratory of Molecular Nuclear Medicine, Tianjin, People's Republic of China
Correspondence: Xiao-Dong Zhang: Fei-Yue Fan

Institute of Radiation Medicine, Chinese Academy of Medical Sciences and Peking Union Medical College, Tianjin 300192,

People's Republic of China

$\mathrm{Tel} / \mathrm{fax}+862285683173$

Email xiaodongzhang@yahoo.cn;

feiyfan@gmail.com
Background: Gold nanoparticle toxicity research is currently leading towards the in vivo experiment. Most toxicology data show that the surface chemistry and physical dimensions of gold nanoparticles play an important role in toxicity. Here, we present the in vivo toxicity of 5, 10, 30, and $60 \mathrm{~nm}$ PEG-coated gold nanoparticles in mice.

Methods: Animal survival, weight, hematology, morphology, organ index, and biochemistry were characterized at a concentration of $4000 \mu \mathrm{g} / \mathrm{kg}$ over 28 days.

Results: The PEG-coated gold particles did not cause an obvious decrease in body weight or appreciable toxicity even after their breakdown in vivo. Biodistribution results show that $5 \mathrm{~nm}$ and $10 \mathrm{~nm}$ particles accumulated in the liver and that $30 \mathrm{~nm}$ particles accumulated in the spleen, while the $60 \mathrm{~nm}$ particles did not accumulate to an appreciable extent in either organ. Transmission electron microscopic observations showed that the 5, 10,30, and $60 \mathrm{~nm}$ particles located in the blood and bone marrow cells, and that the 5 and $60 \mathrm{~nm}$ particles aggregated preferentially in the blood cells. The increase in spleen index and thymus index shows that the immune system can be affected by these small nanoparticles. The $10 \mathrm{~nm}$ gold particles induced an increase in white blood cells, while the $5 \mathrm{~nm}$ and $30 \mathrm{~nm}$ particles induced a decrease in white blood cells and red blood cells. The biochemistry results show that the $10 \mathrm{~nm}$ and $60 \mathrm{~nm}$ PEG-coated gold nanoparticles caused a significant increase in alanine transaminase and aspartate transaminase levels, indicating slight damage to the liver.

Conclusion: The toxicity of PEG-coated gold particles is complex, and it cannot be concluded that the smaller particles have greater toxicity. The toxicity of the $10 \mathrm{~nm}$ and $60 \mathrm{~nm}$ particles was obviously higher than that of the $5 \mathrm{~nm}$ and $30 \mathrm{~nm}$ particles. The metabolism of these particles and protection of the liver will be more important issues for medical applications of gold-based nanomaterials in future.

Keywords: gold nanoparticles, in vivo, toxicity, size

\section{Introduction}

Gold-based nanomaterials have been focused on in diverse biomedical applications due to their unique surface chemistry and optical properties. ${ }^{1,2}$ Because of their strong and size-tunable surface plasmon resonance, fluorescence, and easy surface functionalization, gold-based nanomaterials have been widely used in biosensors, cancer cell imaging, photothermal therapy, and drug delivery. ${ }^{3-9}$ Recently, gold nanoparticles have been suggested as a novel radiosensitizer technique in radiotherapy, because their strong photoelectric absorption and secondary electron caused by gamma or X-ray irradiation can accelerate DNA strand breakage. ${ }^{10-12}$ Therefore, it was necessary to investigate the toxicity of these materials. 
The toxicity of gold-based nanomaterials has been reported in recent years. ${ }^{13-18}$ In general, their toxicity depends on particle size and surface coating. The biosafety of metallic gold is well known. Gold was used in vivo in the 1950s, but functionalized gold particles showed obvious cytotoxicity. ${ }^{19}$ Recently, the cytotoxicity of gold nanoparticles in human cells was studied in detail, and the results showed that these nanoparticles were nontoxic up to $250 \mathrm{mM}$, while ionic gold showed obvious cytotoxicity at $25 \mathrm{mM} .{ }^{20}$ Similar results were also reported recently using gold nanoparticles in radiotherapy experiments in vitro. ${ }^{21-28}$ However, in vitro systems cannot replicate the complexity of an in vivo system or provide meaningful data about the response of a physiological system to an agent. A case in point is carbon nanotubes. ${ }^{29}$ Manna et al ${ }^{29}$ found them to be toxic in vitro, whereas Schipper et al found no significant toxicity in vivo. ${ }^{30}$ Similarly, Sayes et al found that in vivo toxicology results for fullerenes were very different from in vitro data. ${ }^{31}$

Therefore, the in vivo toxicity of gold nanoparticles is important. Very recently, size-dependent organ distribution of gold nanoparticles has been investigated, and the results showed that small gold nanoparticles of 5-15 $\mathrm{nm}$ had a wider organ distribution than that of larger gold nanoparticles of 50-100 nm, with the liver and spleen being the dominant targeted organs. ${ }^{32-37}$ Meanwhile, it has been found that gold nanoparticles with a long blood circulation time can accumulate in the liver and spleen, and have obvious effects on gene expression. ${ }^{38-40}$ Furthermore, the toxicity and biodistribution of polyethylene glycol (PEG)-coated gold nanoparticles have also been investigated, and the results showed that $20 \mathrm{~nm}$ gold nanoparticles coated with TA-terminated $\mathrm{PEG}_{5000}$ were the most stable, and had the lowest toxicity among the 20 , 40 , and $80 \mathrm{~nm}$ gold nanoparticles coated with TA-terminated $\mathrm{PEG}_{5000}{ }^{36,38,41,42}$ However, the PEG-coated gold nanoparticles had a very low zeta potential which was significantly different from that of naked gold nanoparticles. For example, it has been reported that $13.5 \mathrm{~nm}$ PEG-coated gold nanoparticles can damage the liver and that $100 \mathrm{~nm}$ particles can be cleared partially. ${ }^{36,38}$ Therefore, it is desirable to clarify what size of PEG-coated gold particle is safe.

In previous work, we evaluated the in vitro and in vivo toxicity of naked gold nanoparticles. ${ }^{43,44}$ Here, we investigate the in vivo toxicity of 5, 10,30, and $60 \mathrm{~nm}$ PEG-coated gold nanoparticles by evaluating biodistribution, blood chemistry, biochemistry, and characteristics on transmission electron microscopy. The outcome of this research will determine which size would be suitable for photothermal therapy and radiotherapy. Furthermore, the relevant hematology parameters of organs were analyzed.

\section{Materials and methods Fabrication of gold nanoparticles}

The gold nanoparticles were fabricated following the classical method devised by Turkevich et al..$^{45}$ A $100 \mathrm{~mL}$ aliquot of $0.01 \%$ chloroauric acid $\left(\mathrm{HAuCl}_{4} \cdot 4 \mathrm{H}_{2} \mathrm{O}\right)$ solution was refluxed, and $0.8,1.3$, and $5 \mathrm{~mL}$ of $1 \%$ sodium citrate solution was then added to the boiling solution. Reduction of gold ions by the citrate ions was complete after 5 minutes, and the solution was then boiled for a further 30 minutes and left to cool to room temperature. This method yielded spherical particles with an average diameter of about 10, 30, and $60 \mathrm{~nm}$. The small-sized gold nanoparticles of $5 \mathrm{~nm}$ were reduced by $\mathrm{NaBH}_{4}$. Subsequently, PEG-SH (Sigma-Aldrich, St Louis, MO) $1 \mathrm{mg}$ was mixed with the gold nanoparticles and stirred for 1 hour to modify the surface of the gold nanoparticles covalently with PEG. The resulting PEG-coated gold nanoparticles were collected by centrifugation at 16,000 rpm for 30 minutes and washed twice with distilled water. The PEG-coated gold nanoparticle solution was stored at $4^{\circ} \mathrm{C}$ in order to prevent aggregation. Although the mean size varied slightly for each preparation, the size distribution was always found to be less than $20 \%$ of the standard deviation shown in Figure 1.

The zeta potential for the gold nanoparticles was determined using a Nano Zetasizer particle analyzer (Malvern Instruments, Worcestershire, UK). Data in the phase analysis were acquired in the light scattering mode at $25^{\circ} \mathrm{C}$, and sample solutions were prepared by diluting the gold nanoparticles in $10 \mathrm{mM}$ phosphate-buffered saline solution ( $\mathrm{pH}$ 7.0). The zeta potential of the 5, 10,30, and $60 \mathrm{~nm}$ naked gold particles was $-22.1,-28.23,-26.7$, and $-12.27 \mathrm{mV}$, respectively. Due to citric acid coating and the negative surface charge, PEG-SH coating decreased the zeta potential to $-2.96,-1.55,-1.97$, and $-1.65 \mathrm{mV}$, respectively.

The size and morphology of the gold nanoparticles were analyzed by transmission electron microscopy using a Hitachi HF-2000 field emission high-resolution transmission electron microscope operating at $200 \mathrm{kV}$. The optical absorption spectra in a wavelength range of $200-850 \mathrm{~nm}$ was measured in a $5 \mathrm{~mL}$ glass cuvette using a DU800 spectrometer.

\section{In vivo study design}

The animals are purchased, maintained, and handled according to protocols approved by the Institute of Radiation 

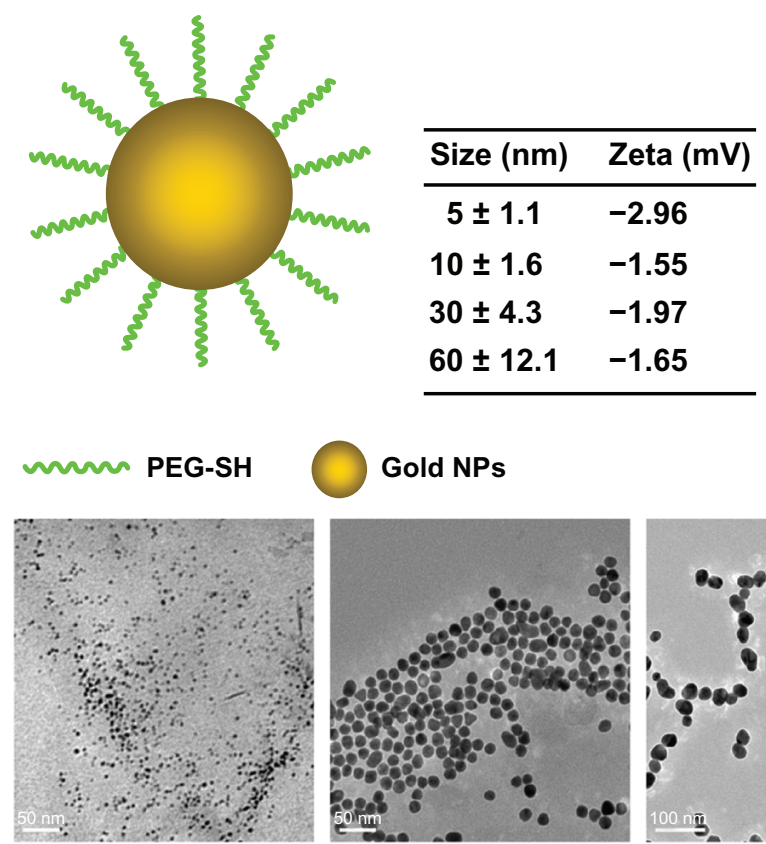

\section{Gold NPs}
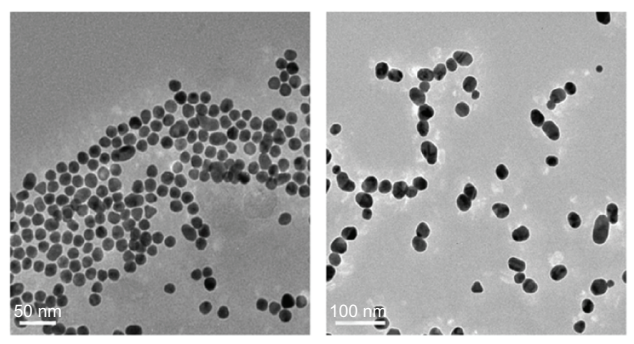
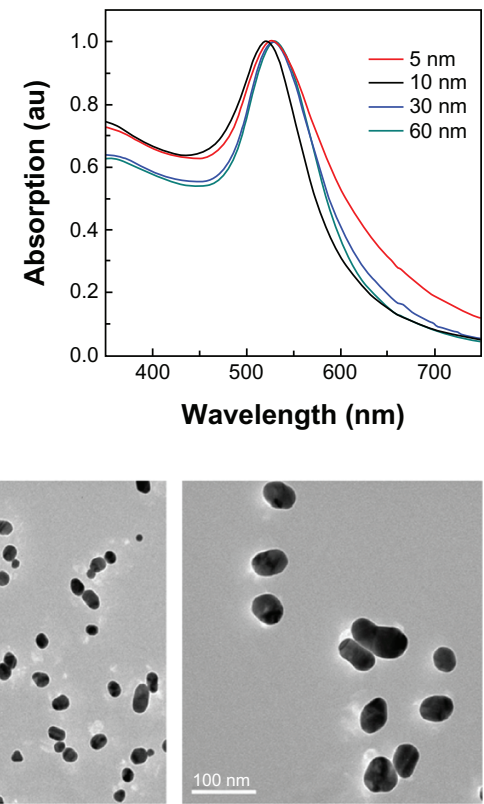

Figure I Transmission electron micrographs and optical absorption of 5, 10, 30, and $60 \mathrm{~nm}$ PEG-coated gold particles.

Medicine, Chinese Academy of Medical Sciences. Male mice were obtained from the Institute of Radiation Medicine laboratory at 11 weeks of age and were housed on a 12-hour light/12-hour dark cycle, and had access to food and water ad libitum. In the size-dependent toxicology experiment, 30 mice were randomly divided into five groups (six mice in each group) comprising one control group and four experimental groups for administration of different sizes of gold nanoparticles. The mice received an intraperitoneal injection of approximately $200 \mu \mathrm{L}$ of gold nanoparticle solution at a dose of $4000 \mu \mathrm{g} / \mathrm{kg}$, based on the previously identified toxic dose in vivo. ${ }^{44}$ The mice were weighed following injection and assessed for behavioral changes every day for 28 days.

\section{Hematology, biochemistry, and sample collection}

Using a standard blood collection technique, blood was drawn from the saphenous vein into a potassium ethylenediamine tetra-acetic acid collection tube for hematology analysis. Analysis of standard hematological parameters was performed. For blood analysis, $300 \mu \mathrm{L}$ of blood was collected from the mice. At 28 days, the mice were sacrificed by isoflurane anesthetic and exsanguinated with phosphate-buffered saline using an angiocatheter. One mouse from each treatment group was fixed with $10 \%$ buffered formalin following exsanguination. The liver, kidneys, spleen, heart, lungs, thyroid, lymph nodes, and bone marrow were then collected and weighed.
The spleen and thymus indices $\left(\mathrm{S}_{x}\right)$ can be expressed as:

$$
\mathrm{S}_{x}=\frac{\text { Weight of experimental organ }(\mathrm{mg})}{\text { Weight of experimental animal }}
$$

\section{Transmission electron microscopic analysis}

Bone marrow and blood cells were obtained after 28 days of administration of a nanoparticle dose of $4000 \mu \mathrm{g} / \mathrm{kg}$. For the transmission electron microscopy analysis, the solution was centrifuged and the pellet fixed with $2.5 \%$ glutaraldehyde in $0.03 \mathrm{M}$ potassium phosphate buffer ( $\mathrm{pH}$ 7.4). The cells were postfixed with $1 \%$ osmium tetroxide in $0.1 \mathrm{M}$ sodium cacodylate buffer, and $0.5 \%$ uranyl acetate in $0.05 \mathrm{M}$ maleate buffer. Cells are then dehydrated in a graded series of ethanol and embedded in Epon resin. Ultrathin sections were cut and transferred onto 200 mesh uncoated copper grids, stained with uranyl acetate, counterstained with lead citrate, and observed using an Hitachi HF-2000 field emission high-resolution transmission electron microscope operating at $200 \mathrm{kV}$.

\section{Results and discussion Body weight and biodistribution}

Figure 2 shows the variations in body weight of mice treated with different-sized gold nanoparticles. It can be seen that PEG-coated nanoparticles at a dose of $4000 \mu \mathrm{g} / \mathrm{kg}$ did not 


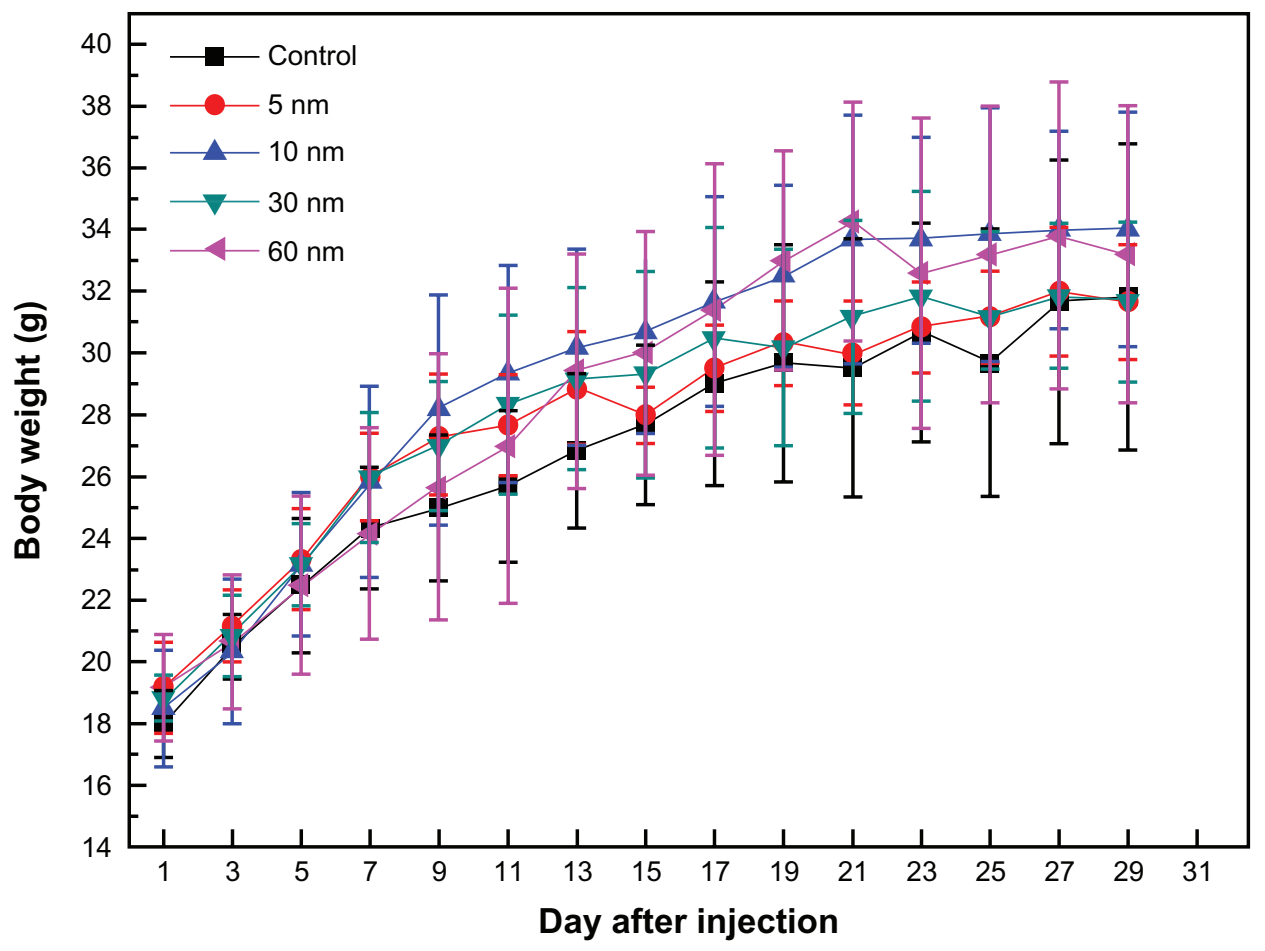

Figure 2 Body weight changes in mice for the 5, 10, 30, and $60 \mathrm{~nm}$ PEG-coated gold particles at a dose of $4000 \mu \mathrm{g} / \mathrm{kg}$. The body weight of the treated mice was measured every 2 days. Each point represents the mean \pm standard deviation of six mice. Data were analyzed using the Student's $t$-test and the differences between the different doses and control group for each organ were not significant $(P>0.05)$.

cause any deaths, and that body weight was slightly higher than in the control group during a 1-day observation period. The body weight of mice which received the $5 \mathrm{~nm}$ particles was slightly different from the other groups. During the study period, treatment with gold nanoparticles for 28 days did not cause obvious adverse effects on growth because no statistically significant differences in weight gain were observed between the gold nanoparticle-treated mice and the control mice. Furthermore, no abnormal clinical signs or behaviors were detected in either the controls and treated groups. Considered overall, treatment with gold nanoparticles did not induce any apparent toxicity in the mice. Necropsy at the end of the experiment did not show any macroscopic changes in the organs in any of the four treatment groups.

To demonstrate the biodistribution of the PEG-coated gold nanoparticles, gold concentrations in the heart, liver, spleen, and kidney after 28 days are shown in Figure 3. It can be seen that concentrations of the $5,10,30$, and $60 \mathrm{~nm}$ particles in the heart were $214,18,8.6$, and $37 \mu \mathrm{g} / \mathrm{kg}$, respectively, with the $5 \mathrm{~nm}$ particles showing the highest concentration. These gold concentrations are markedly higher than previous biodistribution results. ${ }^{42}$ For the liver, the gold concentrations achieved by the $5,10,30$, and $60 \mathrm{~nm}$ particles were $1797,2898,21$, and $432 \mu \mathrm{g} / \mathrm{kg}$, respectively. It was found that the $5 \mathrm{~nm}$ and $10 \mathrm{~nm}$ particles had a very high concentration in the liver, which is in good agreement with previous work. ${ }^{42}$ For the spleen, the gold concentrations achieved by the $5,10,30$, and $60 \mathrm{~nm}$ particles were 628,138 , 3363, and $721 \mu \mathrm{g} / \mathrm{kg}$, respectively, with the $30 \mathrm{~nm}$ PEGcoated gold particles showing the highest gold concentration. Finally, we showed that the gold concentrations achieved by $5,10,30$, and $60 \mathrm{~nm}$ particles in the kidney were 390 , 48,151 , and $14 \mu \mathrm{g} / \mathrm{kg}$, respectively, with the $5 \mathrm{~nm}$ particles showing the highest gold concentration. The $5 \mathrm{~nm}$ particles had the widest distribution, and the $60 \mathrm{~nm}$ particles showed the lowest concentration in all organs examined.

It is well known that the size and surface-capping of gold nanoparticles play an important role in their biodistribution in mice. ${ }^{36-41}$ It has been shown that naked gold can accumulate in the liver and spleen, and that the spleen and liver are the dominant target organs. ${ }^{32,33}$ Small-sized particles have a wider distribution, and larger-sized particles preferentially accumulate in the liver and spleen. ${ }^{34,35}$ Furthermore, the different surface charge on gold nanoparticles can influence their distribution. PEG-coated gold nanoparticles have a neutral charge, so their dynamic behavior in mice should be different from that of naked and alternatively coated gold nanoparticles. ${ }^{36-38}$ Therefore, we can conclude that the liver is the dominant target organ for $5 \mathrm{~nm}$ and $10 \mathrm{~nm}$ PEG-coated gold particles, and that the spleen is the dominant target organ for the $30 \mathrm{~nm}$ particles. 

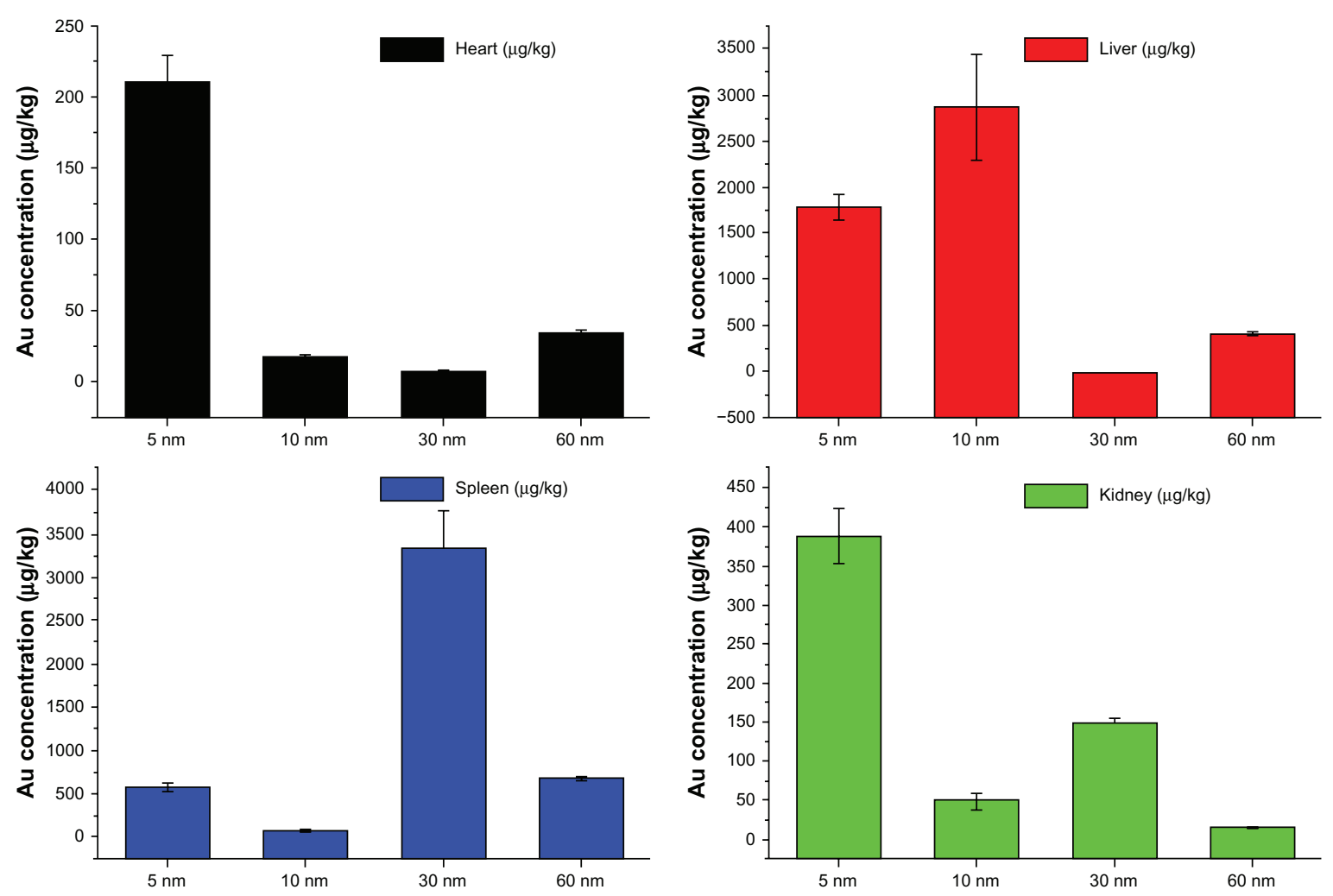

Figure 3 Biodistribution of body weight in mice for 5, 10, 30, and $60 \mathrm{~nm}$ PEG-coated gold particles at the dose of $4000 \mu \mathrm{g} / \mathrm{kg}$ after 28 days of treatment. Spleen and liver were the main target accumulation organs. The $5 \mathrm{~nm}$ particles had a wide distribution in live, heart, kidney, while the 10 and $30 \mathrm{~nm}$ particles preferentially stayed in the liver and spleen, respectively.

The $60 \mathrm{~nm}$ PEG-coated gold particles, similar to previously reported $100 \mathrm{~nm}$ gold particles, have a low distribution in all organs, ${ }^{36}$ and our results show that $60 \mathrm{~nm}$ gold particles can be metabolized partially by the liver and kidney. However, the smaller-sized $5 \mathrm{~nm}$ and $10 \mathrm{~nm}$ gold nanoparticles showed high accumulation and were difficult to metabolize. Indeed, previous biodistribution and pharmacokinetic studies of PEGylated gold nanoparticles have demonstrated high colloidal stability, nonaggregation, and nontoxicity for $20 \mathrm{~nm}$ PEG-coated gold nanoparticles. ${ }^{41}$ Other recent work carried out by Cho et al showed that $13 \mathrm{~nm}$ PEG-coated gold nanoparticles could induce acute inflammation and apoptosis in the liver, and were found to accumulate in the liver and spleen for up to 7 days after tail vein injection and to have a long blood circulation time. ${ }^{38}$ The results reported by Cho et al demonstrated organ micropathology, indicating that gold nanoparticles potentially induce long-term organ damage and toxicity. ${ }^{38}$

\section{Morphology of gold nanoparticles in blood and bone marrow cells}

Figure 4 shows transmission electron microscopic images of $5,10,30$, and $60 \mathrm{~nm}$ gold particles in blood and bone marrow cells after intraperitoneal injection at a dose of $4000 \mu \mathrm{g} / \mathrm{kg}$ for 28 days. The gold nanoparticles were found as monodispersed particles within the bone marrow cells. The $5 \mathrm{~nm}$ particles were found in bone marrow cells, with no significant decrease in size, demonstrating that the small particles did not undergo any obvious breakdown. The 10,30, and $60 \mathrm{~nm}$ particles could be found easily in both the intracellular and extracellular environment, which indicates that these gold particles have a long time retention in the bone marrow, and is in good agreement with previous work. ${ }^{36,38}$ However, in the blood cells, the morphology of the gold particles is different from that in bone marrow cells. The $5 \mathrm{~nm}$ nanoparticles showed good aggregation and hybridization with macromolecules, and could form 10-20 nm compounds. A similar phenomenon was observed for the 10 and $60 \mathrm{~nm}$ gold particles but not the $30 \mathrm{~nm}$ particles. The gold nanoparticles could be found in the blood cells easily, because of surface chemistry and endocytosis. It is noteworthy that the gold nanoparticles could still be found in the blood cells 28 days after administration, which indicates that the gold nanoparticles have a long blood circulation time, and is again in good agreement with previous reports. ${ }^{38-40}$ It has been suggested that interaction between protein and the gold nanoparticles may be closely related to the toxicity of 


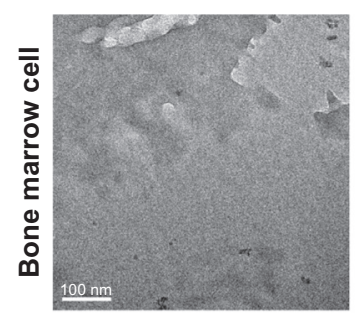

$5 \mathrm{~nm}$

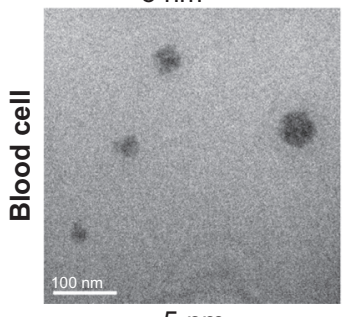

$5 \mathrm{~nm}$

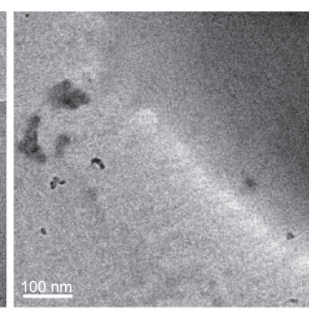

$10 \mathrm{~nm}$

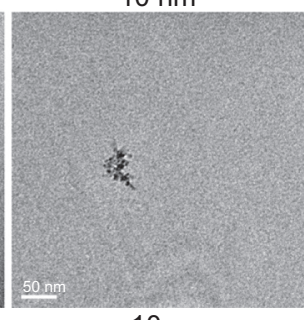

$10 \mathrm{~nm}$

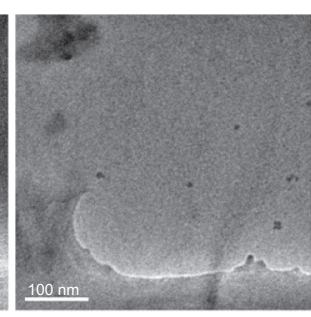

$30 \mathrm{~nm}$

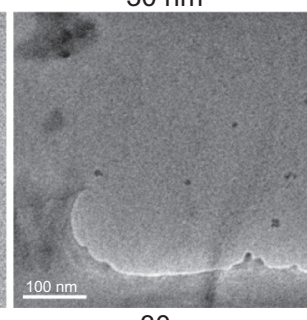

$30 \mathrm{~nm}$

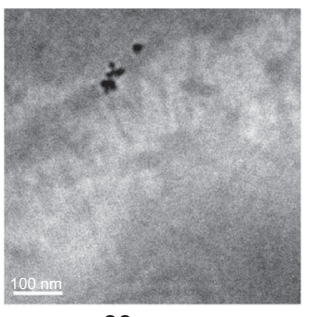

$60 \mathrm{~nm}$

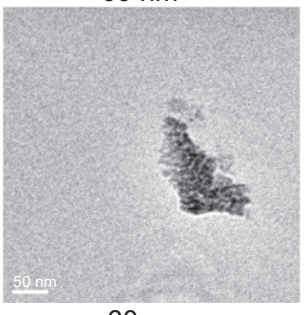

$60 \mathrm{~nm}$

Figure 4 Transmission electron micrographs of 5, 10, 30, and $60 \mathrm{~nm}$ PEG-coated gold particles in bone marrow and blood cells 28 days after intraperitoneal injection at a dose of $4000 \mu \mathrm{g} / \mathrm{kg}$. In the bone marrow cells, the gold particles can be found as monodispersed particles, and aggregations of $10 \mathrm{~nm}$ and $60 \mathrm{~nm}$ particles are found in the blood cells.

the latter. ${ }^{27}$ The surface of a PEG-coated gold nanoparticle probably has a low zeta potential, and cellular uptake of these nanoparticles is different from that of naked gold nanoparticles. The PEG-coated gold nanoparticles can also interact with the cell by endocytosis and a conformational change in the protein, although PEG-coated gold particles have a low charge in the surface.

Endocytosis plays an important role in the interaction between gold nanoparticles and cells, and the PEGcoated gold nanoparticles are different from naked gold nanoparticles. Recent quantitative evaluation revealed that the surface coating on gold nanoparticles could modulate endocytotic uptake pathways and cellular trafficking of the nanoparticles. The naked gold nanoparticles were shown to be taken up by macropinocytosis as well as by clathrinmediated and caveolin-mediated endocytosis. ${ }^{46-48}$ The difference is due to interactions with different proteins or lipids, related to mechanisms of uptake and endocytosis. Increased transcytosis of PEG-coated gold nanoparticles has been observed and a significant number of PEG-coated gold nanoparticles were measured. ${ }^{49}$ Thus, further study is necessary to understand how the mechanism of endocytosis and the protein adsorption process changes the protein conformation and the tendency of $5 \mathrm{~nm}$ and $60 \mathrm{~nm}$ PEGcoated gold particles to aggregate.

\section{Organ indices, hematology, and biochemistry results}

Table 1 gives the organ weights of mice for the different nanoparticle sizes, and illustrates the effect of the PEG-coated gold nanoparticles on the organs. It can be seen that the weights of the heart, liver, spleen, lung, and kidneys showed no obvious variation at the dose of $4000 \mu \mathrm{g} / \mathrm{kg}$. However, the weight of the thymus increased with increasing particle size, but no statistically significant differences were found in these data. To demonstrate the immune reaction in the organs further, the organ indices for the thymus and spleen are shown in Figure 5. The average values of the thymus and spleen indices in the control

Table I Weights for the liver, lung, spleen, kidneys, heart, and thymus for 5, 10, 30, and $60 \mathrm{~nm}$ PEG-coated gold particles at a dose of $4000 \mu \mathrm{g} / \mathrm{kg}$ after 28 days

\begin{tabular}{llllll}
\hline Dose $(\mu \mathbf{g} / \mathbf{k g})$ & Control & $\mathbf{5} \mathbf{~ n m}$ & $\mathbf{1 0} \mathbf{~ n m}$ & $\mathbf{3 0} \mathbf{n m}$ & $\mathbf{6 0} \mathbf{n m}$ \\
\hline Heart $(\mathrm{g})$ & $0.137 \pm 0.019$ & $0.149 \pm 0.013$ & $0.139 \pm 0.017$ & $0.173 \pm 0.019$ & $0.122 \pm 0.008$ \\
Liver $(\mathrm{g})$ & $1.496 \pm 0.203$ & $1.248 \pm 0.102$ & $1.748 \pm 0.326$ & $2.520 \pm 0.544$ & $1.787 \pm 0.222$ \\
Spleen $(\mathrm{g})$ & $0.125 \pm 0.034$ & $0.126 \pm 0.010$ & $0.143 \pm 0.038$ & $0.196 \pm 0.073$ & $0.229 \pm 0.055$ \\
Lung $(\mathrm{g})$ & $0.183 \pm 0.004$ & $0.192 \pm 0.018$ & $0.199 \pm 0.008$ & $0.195 \pm 0.028$ & $0.176 \pm 0.014$ \\
Kidneys $(\mathrm{g})$ & $0.301 \pm 0.037$ & $0.335 \pm 0.033$ & $0.373 \pm 0.100$ & $0.456 \pm 0.019$ & $0.330 \pm 0.035$ \\
Thymus $(\mathrm{g})$ & $0.008 \pm 0.011$ & $0.099 \pm 0.015$ & $0.095 \pm 0.010$ & $0.104 \pm 0.013$ & $0.095 \pm 0.025$ \\
\hline
\end{tabular}

Notes: Data were analyzed by the Student's $t$-test and the differences between the different doses for each organ were not significant ( $P>0.05$ vs controls). All values represent the mean \pm standard deviation of six mice. 
group were 2.3 and 3.3, respectively. The spleen indices of the mice treated with the $5,10,30$, and $60 \mathrm{~nm}$ particles changed to $3.7,4.1,3.3$, and 4.3, respectively, at a gold nanoparticle dose of $4000 \mu \mathrm{g} / \mathrm{kg}$. The thymus indices for the mice treated with the $5,10,30$, and $60 \mathrm{~nm}$ particles changed to $2.2,2.7,3.3$, and 2.5, respectively, at a gold nanoparticle dose of $4000 \mu \mathrm{g} / \mathrm{kg}$. There were still no statistically significant differences between the treated groups and the control group, showing that injections of PEG-coated gold nanoparticles of different sizes do not cause obvious immune effects in either the thymus or spleen. The thymus index increased for all sizes, except for $10 \mathrm{~nm}$. The spleen index increased for all particle sizes. Combining the variations of body weight and biodistribution, it can be seen that the PEG-coated gold nanoparticles had only a slight influence on the mice compared with the naked gold nanoparticles. Moreover, the results imply that the spleen is one of the target organs for PEG-coated gold nanoparticles, which is in good agreement with previous work. ${ }^{32-42,50}$ The liver and spleen have been described as the two dominant organs for biodistribution and metabolism of gold nanoparticles. ${ }^{32-42}$

To quantify the toxicity of the PEG-coated gold nanoparticles, the next important step is assessment of

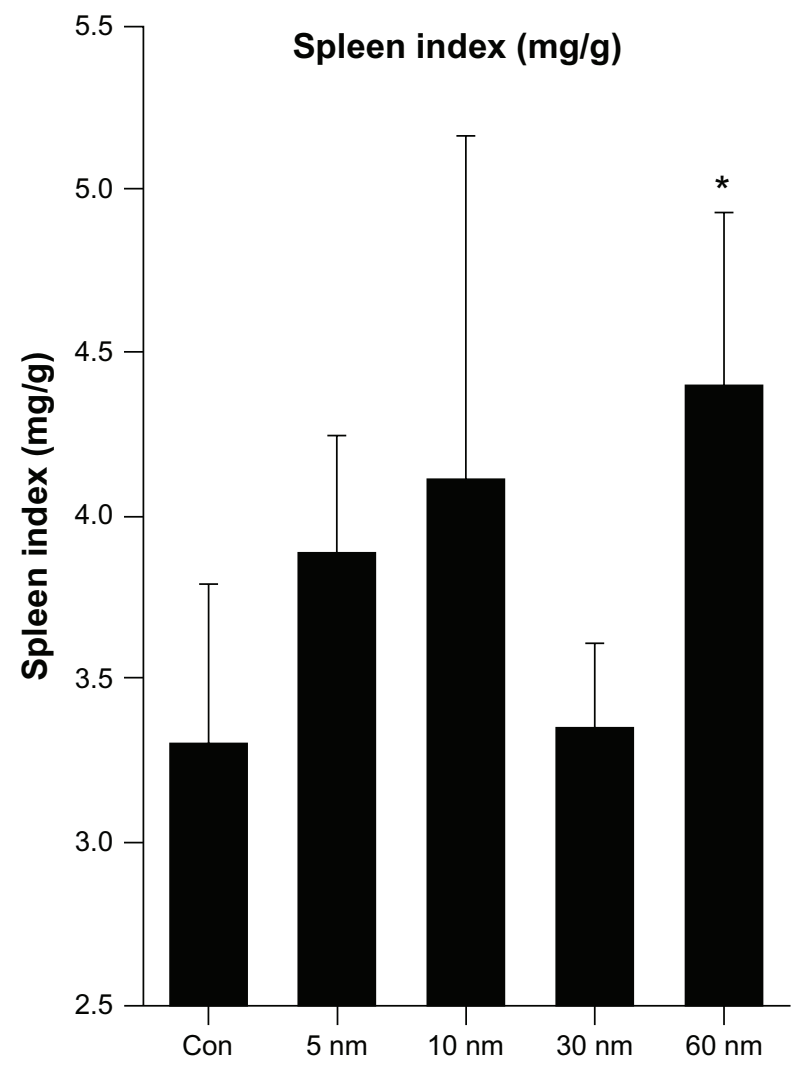

standard hematology and biochemistry, which is very useful for toxicity. ${ }^{50-53}$ We selected standard hematology markers for analysis, ie, platelets, hematocrit, hemoglobin, red blood cells, white blood cells, mean corpuscular volume, mean corpuscular hemoglobin, and mean corpuscular hemoglobin concentration. Nanoparticle size-dependent hematology results are presented in Figure 6. The white blood cells in mice treated with $5 \mathrm{~nm}$ and $30 \mathrm{~nm}$ particles decreased significantly, while white blood cells from mice treated with $10 \mathrm{~nm}$ particles increased at a dose of $4000 \mu \mathrm{g} / \mathrm{kg}$. Similarly, red blood cells from mice treated with 5 and $30 \mathrm{~nm}$ particles decreased significantly, while the red blood cells from mice treated with $10 \mathrm{~nm}$ and $60 \mathrm{~nm}$ particles increased. In addition, platelets, hematocrit, and hemoglobin from mice treated with 5 and $10 \mathrm{~nm}$ particles also increased, but this does not indicate a size-dependent trend associated with treatment. The mean corpuscular volume, platelets, mean corpuscular hemoglobin, and mean corpuscular hemoglobin concentration changed, but no statistically significant difference was found.

White blood cells are sensitive to physiological responses in mice. The rise in white blood cells seen in mice treated with

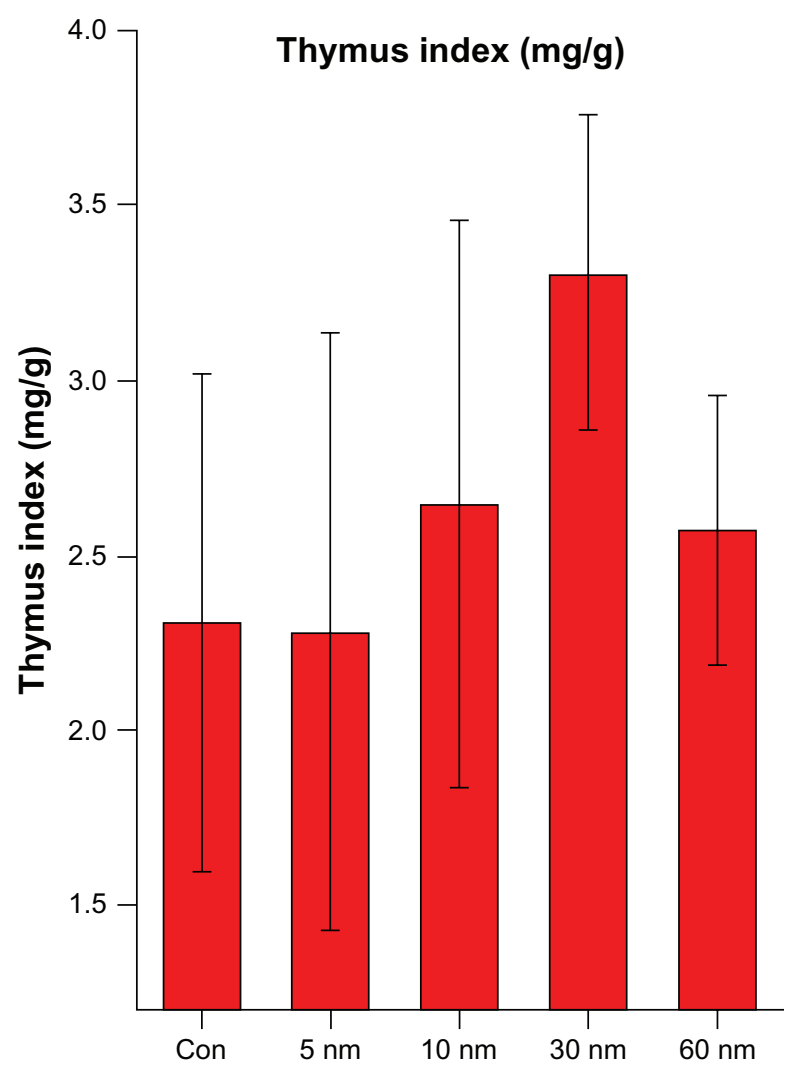

Figure 5 Size-dependent spleen and thymus indices of mice were calculated 28 days after $4000 \mu \mathrm{g} / \mathrm{kg}$ intraperitoneal injections.

Notes: All values are reported as the mean \pm standard deviation. Data were analyzed using Student's $t$-test. "Represents a significant difference from the control group $(P<0.05)$. 

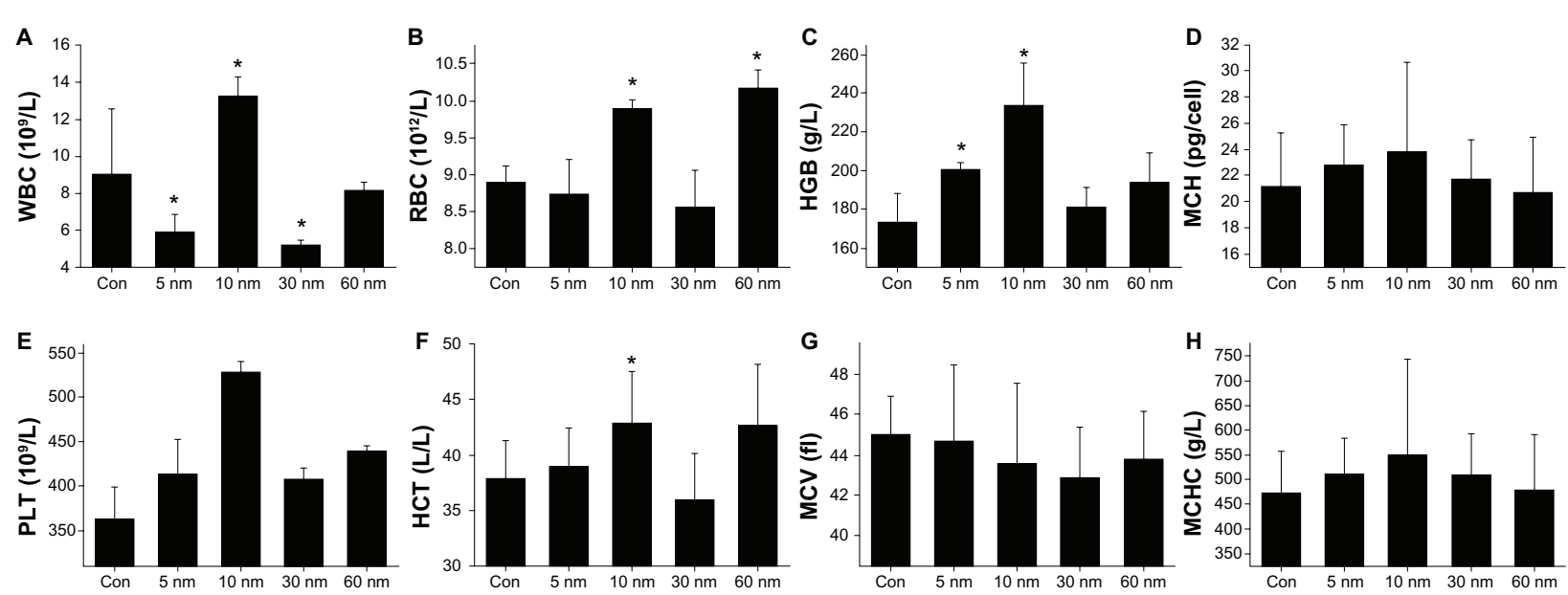

Figure 6 Size-dependent hematology results from mice treated with PEG-coated gold nanoparticles and control group 28 days after intraperitoneal injection at the dose of $4000 \mu \mathrm{g} / \mathrm{kg}$. These results show mean and standard deviations of (A) white blood cells, (B) red blood cell, (C) hemoglobin, (D) mean corpuscular hemoglobin, (E) platelet, (F) hematocrit, (G) mean corpuscular volume, and $(\mathbf{H})$ mean corpuscular hemoglobin concentration.

Notes: Bars represent mean \pm standard deviation. Data were analyzed using the Student's $t$-test. *Represents a significant difference from the control group $(P<0.05)$.

Abbreviations: WBC, white blood cells; RBC, red blood cell; HGB, hemoglobin; MCH, mean corpuscular hemoglobin; PLT, platelet; HCT, hematocrit; MCV, mean corpuscular volume; $\mathrm{MCHC}$, mean corpuscular hemoglobin concentration.

10 and $60 \mathrm{~nm}$ particles indicate an inflammatory response, and the decrease in white blood cells seen in mice treated with $5 \mathrm{~nm}$ and $30 \mathrm{~nm}$ particles may be associated with infection. Red blood cells are derived from hemopoietic stem cells in the bone marrow. Following a series of maturation steps, and directed largely by the hormone erythropoietin, red blood cells enucleate and enter the circulatory system. Thus, any variation in red blood cell levels can be related to the hematopoietic system. The increase in red blood cells found in mice treated with 10 and $60 \mathrm{~nm}$ particles indicates that particles of this size have an effect on the hematopoietic system. The four sizes of gold nanoparticles used in this study could cause different reactions in the mice. The 10 and $60 \mathrm{~nm}$ particles caused a more serious toxic response than the $5 \mathrm{~nm}$ and $30 \mathrm{~nm}$ particles.

Finally, we investigated the biochemical effects of 5, 10, 30, and $60 \mathrm{~nm}$ PEG-coated particles, as shown in Figure 7, including for alanine transaminase, aspartate transaminase, blood urea nitrogen, globulin, creatinine, total protein, albumin, and total bilirubin. It was found that alanine transaminase and aspartate transaminase in mice treated with the 10 and $60 \mathrm{~nm}$ particles increased significantly,
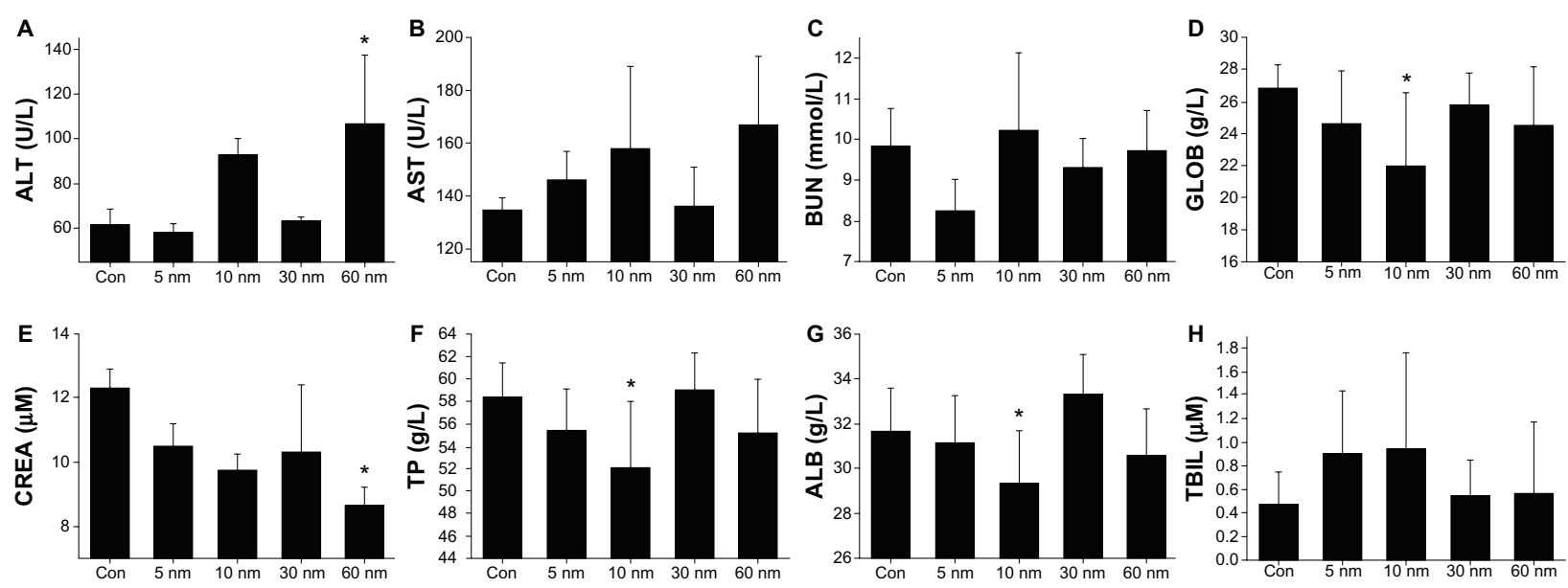

Figure 7 Size-dependent biochemical results for mice treated with PEG-coated gold nanoparticles and control group 28 days after intraperitoneal injection at a dose of $4000 \mu \mathrm{g} / \mathrm{kg}$. These results show mean and standard deviations of $(\mathbf{A})$ alanine transaminase, (B) aspartate transaminase, (C) blood urea nitrogen, (D) globulin, (E) creatinine, (F) total protein, $(\mathbf{G})$ albumin, and $(\mathbf{H})$ total bilirubin.

Notes: Bars represent mean \pm standard deviation. Data were analyzed by Student's $t$-test. "Represents significant difference from the control group $(P<0.05)$.

Abbreviations: ALT, alanine transaminase; AST, aspartate transaminase; BUN, blood urea nitrogen, GLOB, globulin, CREA creatinine; TP, total protein; ALB, albumin; TBIL, total bilirubin. 
and globulin is decreased, indicating that the liver was damaged after injection of the nanoparticles. Creatinine levels in mice treated with the $60 \mathrm{~nm}$ particles decreased sharply, indicating kidney damage in the mice. Total protein and albumin in mice treated with the 10 and $60 \mathrm{~nm}$ particles also decreased after PEG-coated gold injection, while total bilirubin and blood urea nitrogen showed no significant change for any size of particles. These results show clearly that the $10 \mathrm{~nm}$ particles are highly toxic to the liver and that the $60 \mathrm{~nm}$ particles are toxic to both the kidney and liver. However, the $5 \mathrm{~nm}$ and $30 \mathrm{~nm}$ particles did not cause any significant liver and kidney damage.

Alanine transaminase and aspartate transaminase are mainly distributed in liver cells, and their levels rise with necrosis of liver cells. The levels of these enzymes correspond well with the extent of liver cell damage, and are commonly used indicators of liver function. These two enzymes are distributed differently among the liver cells. Alanine transaminase mainly exists in the cytoplasm of liver cells, whereas aspartate transaminase mainly exists in the cytoplasm and mitochondria of liver cells. Therefore, the increase in alanine transaminase in our mice treated with 10 and $60 \mathrm{~nm}$ gold nanoparticles indicates damage to liver cells. However, their biodistribution shows that the concentration reached by $60 \mathrm{~nm}$ gold particles in the liver was not as high as that reached by $10 \mathrm{~nm}$ particles, indicate that the liver damage caused by the $60 \mathrm{~nm}$ particles was due to metabolism of the gold nanoparticles. In contrast, the $5 \mathrm{~nm}$ particles also reached high concentrations in the liver, but liver function was not significantly affected, showing that the $5 \mathrm{~nm}$ particles did not caused direct damage to the liver. The $5 \mathrm{~nm}$ particles are promising for the treatment of liver cancer without liver damage, which is very important for further work.

Creatinine is another important indicator of kidney function. Endogenous human creatinine is a product of muscle metabolism. In muscle, creatine mainly generates creatinine slowly through nonenzymatic dehydration, which is then released into the blood, with excretion in the urine. The serum creatinine concentration depends on the glomerular filtration rate. However, serum creatinine is not entirely consistent with the creatinine clearance rate, and creatinine clearance is more sensitive than serum creatinine. In early renal dysfunction (decompensated), creatinine clearance rate and serum creatinine are normal. When the glomerular filtration rate rises to above $50 \%$ of normal, serum creatinine begins to rise rapidly. Therefore, when the serum creatinine is significantly higher than normal, kidney function is seriously damaged. The decrease in creatinine seen in mice treated with the $60 \mathrm{~nm}$ particles is closely related to kidney function, although the kidney is not the main target organ for gold distribution. The $5 \mathrm{~nm}$ particles did not induce any kidney damage, but the $10 \mathrm{~nm}$ particles caused some damage by decreasing total protein and globulin.

In summary, the $60 \mathrm{~nm}$ particles induced serious toxicity and damage to the liver and kidney, but had a relatively low distribution in the liver, spleen, and kidney. It is proposed that this toxicity may be due to the metabolism of PEG-coated gold particles, which is similar to that previously reported for $100 \mathrm{~nm}$ PEG-coated gold particles. ${ }^{36}$ The toxicity of the $10 \mathrm{~nm}$ particles was also high, due to liver and kidney damage, as well as an inflammatory response, and large amounts of gold can accumulate in the liver. The present results are in good agreement with the results of Cho et al, showing that $13.5 \mathrm{~nm}$ PEG-coated gold particles can induce serious toxicity. ${ }^{36,38}$ Our $5 \mathrm{~nm}$ and $30 \mathrm{~nm}$ particles showed low toxicity, although accumulation of $5 \mathrm{~nm}$ particles did occur in the liver and kidneys, and the $30 \mathrm{~nm}$ particles preferentially remained in the spleen. Therefore, we suggest that $10 \mathrm{~nm}$ PEG-coated gold particles are not sufficiently safe to be administered at a concentration of $4000 \mu \mathrm{g} / \mathrm{kg}$. If we want to use these particles to encapsulate drugs for use in the clinical setting, metabolism must be considered. High accumulation of gold may induce long-term toxicity. The most important finding for the size-dependent toxicity of PEG-coated gold nanoparticles are that the $5 \mathrm{~nm}$ and $30 \mathrm{~nm}$ particles are safe, but the $10 \mathrm{~nm}$ and $60 \mathrm{~nm}$ particles are toxic, which is not consistent with previous in vitro findings, ie, the smaller the particle, the greater the toxicity.

\section{Conclusion}

A size-dependent in vivo toxicity study of PEG-coated gold nanoparticles in mice was carried out. In the study animals, survival, weight, hematology, biochemistry, and morphology were characterized 28 days after administration of the gold nanoparticles at a concentration of $4000 \mu \mathrm{g} / \mathrm{kg}$. Biodistribution studies showed that the spleen and liver are two dominant target organs. Our results showed that the $5 \mathrm{~nm}$ and $10 \mathrm{~nm}$ particles mainly accumulate in the liver, and that the $30 \mathrm{~nm}$ particles preferentially accumulate in the spleen. The $60 \mathrm{~nm}$ particles had a wider distribution, with limited accumulation in the organs. Blood chemistry revealed that white blood cells were increased in mice treated with the $10 \mathrm{~nm}$ and $60 \mathrm{~nm}$ particles, while those treated with the $5 \mathrm{~nm}$ and $30 \mathrm{~nm}$ particles showed decreased white blood cells. Furthermore, alanine transaminase and aspartate transaminase increased in mice treated with the 10 and $60 \mathrm{~nm}$ 
particles, while creatinine decreased with the $60 \mathrm{~nm}$ particles, indicating that the 10 and $60 \mathrm{~nm}$ particles caused liver and kidney damage. The present work clearly shows that 10 and $60 \mathrm{~nm}$ PEG-coated gold nanoparticles are not sufficiently safe, and that the 5 and $30 \mathrm{~nm}$ particles have relatively low toxicity. These conclusions are very important for future cancer therapy, drug delivery, and diagnosis.

\section{Acknowledgments}

The authors would like to thank Professor Warren Chan for his helpful discussions. This work was supported by the National Natural Science Foundation of China (Grant No. 81000668, 30970867), the Specialized Research Fund for the Doctoral Program (SRFDP) of Higher Education State Education Ministry (Grant No. 200800231058), and the Subject Development Foundation of Institute of Radiation Medicine, Chinese Academy of Medical Sciences CAMS.

\section{Disclosure}

The authors report no conflicts of interest in this work.

\section{References}

1. Daniel MC, Astruc D. Gold nanoparticles: assembly, supramolecular chemistry, quantum-size-related properties, and applications toward biology, catalysis, and nanotechnology. Chem Rev. 2004;104: 293-346.

2. Eustis S, El-Sayed MA. Why gold nanoparticles are more precious than pretty gold: noble metal surface plasmon resonance and its enhancement of the radiative and nonradiative properties of nanocrystals of different shapes. Chem Soc Rev. 2006;35:209-217.

3. Hu M, Chen J, Li ZY, et al. Gold nanostructures: engineering their plasmonic properties for biomedical applications. Chem Soc Rev. 2006;35:1084-1094.

4. Anker JN, Hall WP, Lyandres O, Shah NC, Zhao J, Van Duyne RP. Biosensing with plasmonic nanosensors. Nat Mater. 2008;7:442-453.

5. Sokolov K, Follen M, Aaron J, et al. Real-time vital optical imaging of precancer using anti-epidermal growth factor receptor antibodies conjugated to gold nanoparticles. Cancer Res. 2003;63:1999-2004.

6. Link S, El-Sayed MA. Shape and size dependence of radiative, nonradiative and photothermal properties of gold nanocrystals. Int Rev Phys Chem. 2000;19:409-453.

7. Wu D, Zhang XD, Liu PX, Zhang LA, Fan FY, Guo ML. Gold nanostructure: fabrication, surface modification, targeting imaging, and enhanced radiotherapy. Curr Nanosci. 2011;7:110-118.

8. Zheng J, Zhang C, Dickson RM. Highly fluorescent, water-soluble, size-tunable gold quantum dots. Phys Rev Lett. 2004;93:077402.

9. Huang X, El-Sayed IH, Qian W, El-Sayed MA. Cancer cell imaging and photothermal therapy in the near-infrared region by using gold nanorods. J Am Chem Soc. 2006;128:2115-2120.

10. Hainfeld JF, Slatkin DN, Smilowitz HM. The use of gold nanoparticles to enhance radiotherapy in mice. Phys Med Biol. 2004;49:N309-N315.

11. Juzenas P, Chen W, Sun YP, et al. Quantum dots and nanoparticles for photodynamic and radiation therapies of cancer. Adv Drug Deliv Rev. 2008;60:1600-1614.

12. Liu CJ, Wang CH, Chien CC, et al. Enhanced X-ray irradiation-induced cancer cell damage by gold nanoparticles treated by a new synthesis method of polyethylene glycol modification. Nanotech. 2008;19: 295104-295109.
13. Nel A, Xia T, Mädler L, Li N. Toxic potential of materials at the nanolevel. Science. 2006;311:662-627.

14. Chen Z, Meng H, Xing G, et al. Acute toxicological effects of copper nanoparticles in vivo. Toxicol Lett. 2006;163:109-120.

15. Cho EC, Au L, Zhang Q, Xia Y. The effects of size, shape, and surface functional group of gold nanostructures on their adsorption and internalization by cells. Small. 2009;6:517-522.

16. Sayes CM, Reed KL, Warheit DB. Assessing toxicity of fine and nanoparticles: comparing in vitro measurements to in vivo pulmonary toxicity profiles. Toxicol Sci. 2007;97:163-180.

17. Kim JS, Yoon TJ, Yu KN, et al. Toxicity and tissue distribution of magnetic nanoparticles in mice. Toxicol Sci. 2006;89:338-347.

18. Yang ST, Fernando KAS, Liu JH, et al. Covalently PEGylated carbon nanotubes with stealth character in vivo. Small. 2008;4:940-944.

19. Goodman CM, McCusker CD, Yilmaz T, Rotello VM. Toxicity of gold nanoparticles functionalized with cationic and anionic side chains. Bioconjug Chem. 2004;15:897-900.

20. Connor EE, Mwamuka J, Gole A, Murphy CJ, Wyatt MD. Gold nanoparticles are taken up by human cells but do not cause acute cytotoxicity. Small. 2005;1:325-327.

21. Pernodet N, Fang X, Sun Y, et al. Adverse effects of citrate/gold nanoparticles on human dermal fibroblasts. Small. 2006;2:766-773.

22. Lewinski N, Colvin V, Drezek R. Cytotoxicity of nanoparticles. Small. 2008;4:26-49.

23. Murphy CJ, Gole AM, Stone JW, et al. Gold nanoparticles in biology: beyond toxicity to cellular imaging. Acc Chem Res. 2008;41: 1721-1730.

24. Teeguarden JG, Hinderliter PM, Orr G, Thrall BD, Pounds JG. Particokinetics in vitro: dosimetry considerations for in vitro nanoparticle toxicity assessments. Toxicol Sci. 2007;95:300-312.

25. Patra HK, Banerjee S, Chaudhuri U, Lahiri P, Dasgupta A. Cell selective response to gold nanoparticles. Nanomedicine. 2007;3:111-119.

26. Male KB, Lachance B, Hrapovic S, Sunahara G, Luong JH. Assessment of cytotoxicity of quantum dots and gold nanoparticles using cell-based impedance spectroscopy. Anal Chem. 2008;80:5487-5493.

27. Chithrani BD, Ghazani AA, Chan WCW. Determining the size and shape dependence of gold nanoparticle uptake into mammalian cells. Nano Lett. 2006;6:662-668.

28. Pan Y, Neuss S, Leifert A, et al. Size-dependent cytotoxicity of gold nanoparticles. Small. 2007;3:1941-1949.

29. Manna S, Sarkar S, Barr J, Wise K, et al. Single-walled carbon nanotube induces oxidative stress and activates nuclear transcription. Nano Lett. 2005;5:1676-1684.

30. Schipper M, Nakayama-Ratchford N, Davis C, et al. A pilot toxicology study of single-walled carbon nanotubes in a small sample of mice. Nat Nanotechnol. 2008;3:216-221.

31. Sayes CM, Marchione AA, Reed KL, Warheit DB. Comparative pulmonary toxicity assessments of $\mathrm{C}_{60}$ water suspensions in rats: few differences in fullerene toxicity in vivo in contrast to in vitro profiles. Nano Lett. 2007;7:2399-2406.

32. De Jong WH, Hagens WI, Krystek P, Burger MC, Sips AJ, Geertsma RE. Particle size-dependent organ distribution of gold nanoparticles after intravenous administration. Biomaterials. 2008;29:1912-1919.

33. Sonavane G, Tomoda K, Makino K. Biodistribution of colloidal gold nanoparticles after intravenous administration: effect of particle size. Colloids Surf B Biointerfaces. 2008;66:274-280.

34. Kim JH, Kim JH, Kim KW, Kim MH, Yu YS. Intravenously administered gold nanoparticles pass through the blood-retinal barrier depending on the particle size, and induce no retinal toxicity. Nanotechnology. 2009;20:505101.

35. Chen YS, Hung YC, Liau I, Huang GS. Assessment of the in vivo toxicity of gold nanoparticles. Nanoscale Res Lett. 2009;4:858-864.

36. Cho WS, Kim S, Han BS, Son WC, Jeong J. Comparison of gene expression profiles in mice liver following intravenous injection of 4 and 100 nm-sized PEG-coated gold nanoparticles. Toxicol Lett. 2009;191: 96-102. 
37. Semmler-Behnke M, Kreyling WG, Lipka J, et al. Biodistribution of 1.4- and 18-nm gold particles in rats. Small. 2008;4:2108-2111.

38. Cho WS, Cho M, Jeong J, et al. Acute toxicity and pharmacokinetics of 13 nm-sized PEG-coated gold nanoparticles. Toxicol Appl Pharmacol. 2009;236:16-24.

39. Balasubramanian SK, Jittiwat J, Manikandan J, Ong CN, Yu LE, Ong WY. Biodistribution of gold nanoparticles and gene expression changes in the liver and spleen after intravenous administration in rats. Biomaterials. 2010;31:2034-2042.

40. Balogh L, Nigavekar SS, Nair BM, et al. Significant effect of size on the in vivo biodistribution of gold composite nanodevices in mouse tumor models. Nanomedicine. 2007;3:281-296.

41. Zhang G, Yang Z, Lu W, et al. Influence of anchoring ligands and particle size on the colloidal stability and in vivo biodistribution of polyethylene glycol-coated gold nanoparticles in tumor-xenografted mice. Biomaterials. 2009;30:1928-1936.

42. Lipka J, Semmler-Behnke M, Sperling RA, et al. Biodistribution of PEG-modified gold nanoparticles following intratracheal instillation and intravenous injection. Biomaterials. 2010;31:6574-6581.

43. Zhang XD, Guo ML, Wu HY, et al. Irradiation stability and cytotoxicity of gold nanoparticles for radiotherapy. Int J Nanomedicine. 2009;4: $165-173$

44. Zhang XD, Wu HY, Wu D, et al. Toxicologic effects of gold nanoparticles in vivo by different administration routes. Int $J$ Nanomedicine. 2010;5:771-781.

45. Turkevich J, Stevenson PC, Hillier J. A study of the nucleation and growth processes in the synthesis of colloidal gold. Discuss Faraday Soc. 1951;11:55-75.
46. Brandenberger C, Muhlfeld C, Ali Z, et al. Quantitative evaluation of cellular uptake and trafficking of plain and polyethylene glycol-coated gold nanoparticles. Small. 2010;15:1669-1678.

47. Lasagna-Reeves C, Gonzalez-Romero D, Barria MA, et al. Bioaccumulation and toxicity of gold nanoparticles after repeated administration in mice. Biochem Biophys Res Commun. 2010;393: 649-655.

48. Shenoy D, Fu W, Li J, et al. Surface functionalization of gold nanoparticles using hetero-bifunctional poly(ethylene glycol) spacer for intracellular tracking and delivery. Int $J$ Nanomedicine. 2006;1: $51-57$.

49. Lacerda SH, Park JJ, Meuse C, et al. Interaction of gold nanoparticles with common human blood proteins. ACS Nano. 2010;4:365-379.

50. Sadauskas E, Danscher G, Stoltenberg M, Vogel U, Larsen A, Wallin $\mathrm{H}$. Protracted elimination of gold nanoparticles from mouse liver. Nanomedicine. 2009;5:162-169.

51. Gjetting T, Arildsen NS, Laulund C, et al. In vitro and in vivo effects of polyethylene glycol (PEG)-modified lipid in DOTAP/ cholesterolmediated gene transfection. Int J Nanomedicine. 2010;5: 371-383.

52. Hauck TS, Anderson RE, Fischer HC, Newbigging S, Chan WC. In vivo quantum-dot toxicity assessment. Small. 2010;6:138-144.

53. Fent GM, Casteel SW, Kim DY, et al. Biodistribution of maltose and gum arabic hybrid gold nanoparticles after intravenous injection in juvenile swine. Nanomedicine. 2009;5:128-135.
International Journal of Nanomedicine

\section{Publish your work in this journal}

The International Journal of Nanomedicine is an international, peerreviewed journal focusing on the application of nanotechnology in diagnostics, therapeutics, and drug delivery systems throughout the biomedical field. This journal is indexed on PubMed Central, MedLine, CAS, SciSearch $®$, Current Contents ${ } /$ Clinical Medicine,

\section{Dovepress}

Journal Citation Reports/Science Edition, EMBase, Scopus and the Elsevier Bibliographic databases. The manuscript management system is completely online and includes a very quick and fair peer-review system, which is all easy to use. Visit http://www.dovepress.com/ testimonials.php to read real quotes from published authors. 